\title{
LA SANIDAD MILITAR DEL EJÉRCITO ESPAÑOL EN LA GUERRA DE 1895 EN CUBA
}

\author{
Yolanda Díaz Martínez \\ Instituto de Historia de Cuba - Palacio Aldama. \\ La Habana (Cuba)
}

\section{RESUMEN}

Durante la última guerra de independencia cubana se combinaron diferentes factores como el clima, la mala alimentación y las continuas marchas que motivaron un debilitamiento en los soldados españoles y un aumento de las enfermedades en las filas del Ejército Español. El estudio de estas enfermedades, muchas de ellas tropicales, su tratamiento y las medidas sanitarias adoptadas (construccción de hospitales, habilitación de edificios, etc.) es un primer paso para conocer el número de soldados afectados por éstas y en qué medida ello afectó en la eficacia del Ejército Español.

\section{SUMMARY}

During the last Cuban Independence War, the combination of several factors like climate, a poor feeding and the continuos movements of the Army, caused a physical weakness and an increment of diseasies among the Spanish soldiers. The study of these diseasies, many of them tropical ones, their treatment and adopted sanitary measures (like the construction of hospitals, the improvement of installations, etc.) can constitute a first step in order to know the number of the soldier infected by these diseasies and in which manners this fact affected the capacity of the Spanish Army.

La Guerra de Independencia de Cuba comprendida en el período de 1895 a 1898, supuso para España destinar a dicha contienda un enorme contingente de fuerzas e innumerables recursos. Dentro de ellos, la Sanidad Militar requirió un gran presupuesto, pues en Cuba el soldado no solo estaba sujeto a las heridas sufridas en combate, sino que el clima imperante, con abundantes precipitaciones durante gran parte del año, era propicio para que éste contrajera numerosas enfermedades propias del trópico; esta circunstancia se veía agravada con la guerra de desgaste desarrollada por el Ejército Libertador, cuyos efectos debilitantes actuaban negativamente sobre el soldado español. 


\section{INFLUENCIA DEL CLIMA Y OTROS FACTORES SOBRE LA SALUD DEL SOLDADO.}

Al comienzo del conflicto los efectos del clima no se hicieron sentir con tanta fuerza sobre los contingentes desembarcados debido a dos causas fundamentales. En primer lugar estos contingentes arribaban en meses que no eran de los peores en cuanto a precipitaciones y el clima en general, y por otra parte la mayoría de ellos procedían de Puerto Rico, país de similares características a las de Cuba, lo que propiciaba que el soldado tuviese cierta aclimatación.

Fue dicha aclimatación uno de los elementos a los que el gobierno español prestó especial atención, por su incidencia en la salud del soldado. Con el propósito de lograrlo se plantearon varias soluciones; una de ellas fue la posibilidad de crear centros para estos fines en Canarias, donde los jóvenes pasaran varias semanas antes de marchar a Cuba o Puerto Rico; otra, situar a los recién llegados a territorio cubano en lugares salubres, a fin de que fuesen adaptándose progresivamente. Entre los sitios propuestos estuvieron San Antonio Abad, Guanajay, Isla de Pinos y Limonar.

Esta intención se basaba en algunos estudios realizados con anterioridad, entre los que se destacan los trabajos del Dr. Ramón Hernández Poggio, que en su libro Aclimatación e higiene de los europeos en Cuba, y posteriormente en el artículo "La aclimatación en Canarias", publicado por la Revista de Sanidad Militar en 1867, hacía un serio estudio de lo que constituía el proceso de aclimatación ${ }^{1}$, y lo propicio que resultaría para el soldado, antes de marchar a Cuba, pasar un tiempo en Canarias o Tenerife, no solo por su similitud con el clima cubano, sino por la existencia en estos lugares de frutas, legumbres, tubérculos y alimentos en general, parecidos a los que consumiría en Cuba.

De cualquier forma, no fue el Dr. H. Poggio el único preocupado por estas cuestiones; en varios números del periódico El Correo Militar, aparecieron reiteradamente artículos partidarios de la creación de centros de aclimatación en Canarias, llegándose a criticar al Ministerio de la Guerra por su indecisión en crear estos centros:

\footnotetext{
Sensible es que el carácter indeciso del Ministerio de la Guerra haya dejado sin efecto su proyecto de establecer en las Islas Canarias un centro de aclimatación para las tropas que han de ser destinadas a Las Antillas. De haberlo verificado, a estas fechas podría disponer de un núcleo importante de tropas ya aclimatadas que podrían estar ya en marcha para Cuba o Puerto Rico, en sustitución de las que desde esta Isla se destinaron a la primera².
}

1 El Doctor Ramón Hernández Poggio trató siempre de hacer ver en sus trabajos, que la aclimatación no hacia inmune al soldado español en Cuba, pues ni tan siquiera los propios cubanos estaban exentos de padecer las enfermedades. Sin embargo, la aclimatación sí facilitaba que el organismo del europeo se fuese adaptando a las modificacioes climatólogicas antes de llegar a territorio cubano, dotándolo así de cierta energía y vigor que le permitiera resistir con mayor efectividad las diversas enfermedades tropicales.

2 Periódico El Correo Militar. Madrid, 1 de marzo de 1895. 
Los efectos del clima se agravaban con las continuas marchas y contramarchas que debía hacer el soldado español, casi sin descanso, bajo el fuerte sol tropical, en ocasiones interrumpido por imprevistos aguaceros. Muchas de estas marchas se realizaban por zonas boscosas, con innumerables pantanos provocados por las incesantes lluvias y poblados de plagas de mosquitos. Además, el soldado se veía obligado en ocasiones a tener que marchar con el fango hasta las rodillas y mojado, careciendo en la mayoría de los casos de un lugar donde guarecerse. Por esta razón, muchas veces era imposible cambiar las ropas húmedas por secas, propiciando el enfriamiento del organismo, todo lo cual era nefasto para la salud del combatiente.

Para dar solución a esta dificultad se propuso la transformación del vestuario, procurando proveerlo de un uniforme cuyo tejido fuera más fresco para el clima cubano y por otra parte no facilitara el rápido enfriamiento del organismo cuando sudaba o era sorprendido por la lluvia. Además, la frecuencia con que el soldado español acampaba a la intemperie y en suelos con gran humedad eran también elementos a tener en cuenta. De ahí que se recomendara dotar al recluta de polainas y, sobre todo, de camisas de lana o franela, que facilitaran el mantenimiento de la temperatura del organismo.

Sin embargo, no siempre fue posible sustituir los uniformes tradicionalmente confeccionados con tejidos de dril o lino. Para su variación debía acudirse a la gestión, en muchas ocasiones, de empresarios privados, debido a la imposibilidad del Ministerio de la Guerra de destinar los recursos necesarios a esta gestión.

Esta circunstancia se agravaba en el propio acto de confección del vestuario y el calzado. A lo largo del conflicto se suscitaron fuertes polémicas acerca del sitio donde debían ser confeccionados. Siempre habían sido realizados en Cuba, pero a finales de 1895 y comienzos de 1896 se trató de favorecer a los comerciantes españoles, estableciéndose su elaboración en la Península ${ }^{3}$.

Independientemente de esta polémica, el mayor perjudicado fue el soldado, bien porque esta circunstancia no garantizaba la cantidad suficiente para la reposición, bien porque la falta de tradición existente en España para la elaboración del calzado y el uniforme les restaba calidad.

Si bien la actividad diaria agotaba al combatiente, la noche tampoco dejaba de ser difícil para su descanso. Lograr conciliar el sueño era, en ocasiones, casi imposible al ser constantemente tiroteados por las fuerzas insurrectas, con el propósito de agudizarles el cansancio, lo cual influía a favor de los cubanos en el enfrentamiento con

3 En los Legajos 281 y 282 del Fondo Asuntos Políticos del Archivo Nacional de Cuba, se recoge abundante información acerca de la polémica entre los fabricantes españoles y los cubanos, sin que finalmente se llegara a acuerdo alguno, aunque se infiere que el soldado al salir de la Península recibía uniforme y calzado y en Cuba se le entregaba cuando era necesaria su sustitución, o cuando producto de la premura no lo recibía en España. 
estas fuerzas. Las dificultades para descansar se veían frecuentemente acrecentadas por las lluvias nocturnas; al respecto, planteaba un soldado:

Después de comer el rancho y pasear un poco, fuimos unos cuantos compañeros a visitar un ingenio o fábrica de azúcar de las inmediaciones..., de vuelta al campamento fuimos a tender las hamacas y descansar para emprender la marcha al día siguiente. Mas no logramos dormir por el terrible aguacero pues nos mojaba el agua que caía ${ }^{4}$.

Los problemas de alimentación del soldado también incidieron negativamente en su debilitamiento. Acostumbrado a ingerir en España una comida rica en grasas, propicia para el clima frío, al arribar a Cuba sufrió un cambio radical, no solo porque el clima no era propio para consumir este tipo de comidas, sino por las limitaciones que la lejanía imponía para poder hacer llegar a la tropa destacada en Cuba el avituallamiento.

Debido a esta circunstancia, y unido a las dificultades que se afrontaba para la conducción de los convoyes desde los centros de aprovisionamiento al sitio de operaciones de las fuerzas españolas, los jefes de tropa tuvieron que acudir reiteradamente al comerciante español radicado en Cuba, o a los comerciantes cubanos, para la adquisición de suministros que regularmente podían ser conseguidos en las factoría ${ }^{5}$, todo lo cual no estaba exento de especulaciones, en ocasiones no eran de la mejor calidad, ni tampoco suficientes para completar la alimentación del soldado.

Generalmente la dieta se basaba en arroz con distintas variedades de legumbres, tubérculos, acompañada de una ración de sardina o chorizo, pan, o a falta de éste una galleta de mala calidad; cuando la suerte era favorable mataban alguna res que era cocida con un poco de sal y agua ${ }^{6}$. La existencia en Cuba de numerosas frutas es un complemento que pudo ser utilizado por el soldado para su alimentación; sin embargo, el desconocimiento de las costumbres y hábitos del país impedía su aprovechamiento.

\section{PRINCIPALES ENFERMEDADES.}

La acción conjunta de factores como el clima, las continuas marchas y las dificultades para la alimentación, fueron elementos que incidieron en el debilitamiento

4 Estas vivencias son tomadas de algunas cartas escritas por el soldado José Ramírez, miembro del Batallón Alcántara a su padre y que bajo el título de "Diario de un soldado" aparecieron publicadas en el periódico El Correo Militar en varios números. El fragmento citado corresponde a la carta con fecha 18 de julio de 1895 .

5 Estas factorías fueron creadas a lo largo de toda la Isla y en ella el Jefe de detall adquiría los productos para la tropa a cuenta del salario de éstos.

6 Se habían establecido tres variantes de ración de etapa para alimentar el soldado, se seleccionaba un producto entre arroz, garbanzos o frijoles, combinado con tocino, o chorizo, o sardina, añadiéndose café, sal, azúcar y vino o aguardiente. Archivo Nacional de Cuba. Fondo Asuntos Políticos, Leg 247, No 7. 
del soldado, propiciando la acción de las enfermedades del trópico, debilitamiento que aumentaba con la humedad. Al respecto el Dr. Hernández Poggio planteaba:

\footnotetext{
... no es solo el calor húmedo uno de los elementos activos de la enfermedad en las regiones tropicales, es también por la debilidad que produce en el organismo, por lo cual las miasmas se absorben con más facilidad y producen sus efectos deletéreos, y dan a las enfermedades de esta zona el sello especial que se advierte en ellas?
}

Esta situación favorecedora de las enfermedades, y las numerosas bajas causadas en las fuerzas españolas, fueron aspectos ampliamente difundidos en los partes oficiales de la época, así como por la prensa española al tanto del conflicto, la que daba mayor relieve a estos decesos que a los acontecidos en acciones armadas.

Por tal razón, en un elevado porcentaje de ocasiones, las cifras sobre mortalidad por enfermedades y epidemias fueron elementos aprovechados por el alto mando español en Cuba y el Gobierno peninsular, para justificar las bajas sufridas por su Ejército, enfrentado al Ejército Libertador proporcionalmente menor en cuanto a hombres y armas; ignorando y subestimando así la táctica y estrategia desplegada por los principales jefes militares cubanos.

No obstante, es justo reconocer que la propagación de enfermedades, favorecidas por las dificultades afrontadas por la Sanidad Militar, produjeron gran cantidad de bajas al Ejército de Operaciones en Cuba durante la campaña de 1895-1898.

Según cifras ofrecidas por Angel de Larra y $\mathrm{Cerezo}^{8}$, en el año 1896, considerado uno de los más críticos por el número de muertes, el mayor porcentaje de éstas fueron a causa de enfermedades, en comparación con las ocurridas por hechos de armas. De estas últimas, la mayor cantidad - 1.543 - era a consecuencia de disparos de fusil Remington, seguidas por el temido machete mambí con 954, arma por la cual el soldado español sentía un profundo respeto, debido a la destreza y agilidad con que era manejado por el soldado insurrecto. De otros sistemas de armas, la cifra de 1.387 no lograba superar a las producidas por el Remington, mientras que 250, aproximadamente, se debían a heridas sufridas por armas blancas en las que no se incluía el machete.

En cuanto a las enfermedades, la fiebre amarilla fue la que más estragos causó, seguida del paludismo y la disentería, aunque no por ello podían subestimarse las provocadas por la fiebre tifoidea y la tuberculosis. El predominio de muertes por fiebre amarilla sobre otras enfermedades no solo en 1896 sino durante todo el desarrollo de la guerra, es fácilmente comprensible por la existencia en Cuba de grandes

\footnotetext{
7 HERNÁNDEZ POGgIO, Ramón (1876) Aclimatación e higiene de los europeos en Cuba. Imprenta de la Revista Médica, Cádiz, p. 42.

8 LARRA y CEREZO, Angel de (1901) Campaña sanitaria en la Guerra de Cuba. Apuntes estadísticos relativos al año 96. Imprenta de Ricardo Rojas, Madrid, p. 37.
} 
plagas de mosquitos, agente trasmisor de la enfermedad . Aun cuando este descubrimiento fue dado a conocer ya en 1881 por el Dr. Carlos J. Finlay, no estaban suficientemente difundidas las medidas necesarias para su erradicación. Además, en muchas ocasiones se culpaba a las miasmas de ser las causantes de estas enfermedades 9 .

Por otra parte, la base del tratamiento era, ante todo, empírica, tratando de detectar la enfermedad en sus comienzos, correspondiendo después el proceso a aplicar a toda infección, para finalizar con la cura de las perturbaciones ocasionadas por la enfermedad. Al respecto escribía el médico inglés M. Stocker, en la Revista de Sanidad Militar:

\footnotetext{
“... no hay tratamiento especial para la fiebre amarilla, no hay más que tener la fortuna de diagnosticar bien y adelantarse con el tratamiento a las complicaciones que son las que matan"10.
}

El paludismo también hizo grandes estragos entre los soldados. Se manifestaba, frecuentemente, con fiebres intermitentes, por lo que podía ser confundido con un estado gripal, razón por la cual el soldado continuaba prestando sus servicios en guarniciones, e incluso en las columnas de operaciones, haciendo sobrehumanos esfuerzos para no desfallecer; hasta que al cabo de los pocos meses el paludismo, en estado crónico ya, engendraba con su anemia característica una depauperación del organismo y graves lesiones viscerales, de tal gravedad que el lesionado caía en un estado caquéctico, que muchas veces le costaba la vida.

La disentería, la fiebre tifoidea y la tuberculosis, fueron también padecidas con cierta frecuencia por el soldado, a causa de la constante humedad, los problemas de alimentación y la ingestión de aguas estancadas y en mal estado. Sin embargo, la presencia de éstas no fue tan significativa como la de las enfermedades mencionadas anteriormente.

En la estadística publicada por Larra y Cerezo sobre la situación sanitaria en 1896, puede apreciarse en cifras las distintas causas de muerte:

\section{Causas de muertes Número de fallecidos}

Fiebre amarilla ............................................ 7.304

Heridas en combate ........................................... 563

Paludismo ...................................................... 374

9 En la época era sostenido el criterio de que las sustancias orgánicas en descomposición, existentes en lugares pantanosos y con poca higiene, producían emanaciones perniciosas, las denominadas miasmas, que al ser respiradas por el soldado y absorbidas por la piel producían enfermedades.

10 STOCKER, M. (1898) “La fiebre amarilla" en Revista de Sanidad Militar, Madrid, $1^{\circ}$ de noviembre. Año X. p 488 . 


\begin{tabular}{|c|c|}
\hline Causas de muertes & Número de fallecidos \\
\hline \multicolumn{2}{|c|}{ 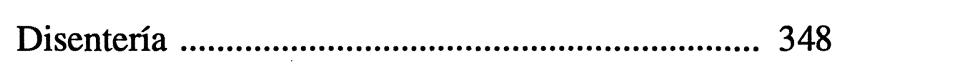 } \\
\hline Fiebre tifoidea .......... & .................. 284 \\
\hline Tuberculosis .............. & ............... 259 \\
\hline Viruelas ......................... & \\
\hline
\end{tabular}

La prensa desempeñó en esta etapa un importante papel en cuanto a la información que brindaba respecto al desenvolvimiento de la contienda en la Isla. Según cifras aparecidas en los periódicos El Imparcial y La Época, el número aproximado de bajas entre febrero de 1895 y octubre de 1896 fue de 14.000, correspondiendo a las ocurridas en combate el $25 \%$, en torno a un $50 \%$ las provocadas por la fiebre amarilla y quedando entre un $20 \%$ y un $25 \%$ para otras enfermedades.

Durante el primer trimestre de 1897 fueron atendidos en los hospitales habaneros, a causa de enfermedades, más de 900 soldados, de los que los contagiados de fiebre amarilla ascendían a 315, y los de paludismo eran más de 100; en total se informó de 205 personas fallecidas.

En el mes de julio, según trabajo elaborado por el corresponsal del periódico $E l$ Imparcial en la Isla, desde el comienzo de la guerra hasta junio de 1897, se había comunicado más de 30.000 enfermos, producto de las incesantes lluvias, sin que se advirtiera una tendencia a la mejoría.

La precaria situación de salud del soldado no mejoró durante 1897, sino todo lo contrario. La Tesis Doctoral de Octavio Avelino Delgado, The Spanish Army in Cuba 1868-1898. An institutional study, ofrece interesantes cifras al respecto del comportamiento de la sanidad en ese año.

Continuaban siendo inferiores las bajas por encuentros en comparación con las debidas a las enfermedades. Las primeras de ellas arrojaban una cifra que apenas sobrepasaba las 1.000 defunciones. En cambio, solamente la fiebre amarilla produjo aportó 5.200 bajas, mientras que al resto de las enfermedades correspondía un número de 11.000 defunciones.

Quizás constituye un elemento más interesante que la totalidad de muertes, el hecho de establecer diferenciadamente el número de fallecidos de las distintas Armas. De todas, la más afectada fue la Infantería, seguida por la Caballería, posteriormente las guerrillas y, finalmente, el Cuerpo de Ingenieros. Las fuerzas menos afectadas fueron la Artillería y la Infantería de Marina.

El hecho de ser la Infantería la fuerza más azotada por la fiebre amarilla y el resto de las enfermedades, estuvo condicionado, en gran medida, por ser ésta la que mayor número de fuerzas tenía destacadas en la Isla y, por otra parte, ser la fuerza que más expuesta estaba a sufrir los embates del clima, por el agotamiento que le causaba la incesante actividad. 
En cuanto al número de fallecidos en relación con el grado militar, el soldado era el más afectado. En escala regresiva le seguían: cabos, sargentos, segundos tenientes, capitanes mayores, tenientes coroneles y coroneles. Las penalidades que sufría el soldado durante las constantes marchas y contramarchas, así como las dificultades para garantizar una adecuada alimentación, fueron elementos que incidieron en que fueran ellos los más sufridos del Ejército de Operaciones de Cuba.

Algunos autores de la época ofrecen cifras generales sobre las muertes acaecidas en Cuba durante el desarrollo de la guerra. Manuel Baraja Montana, en su libro La Guerra de Cuba a través del Diario de Cádiz, a partir de cifras parciales ofrecidas por otros autores y datos de prensa, plantea un número total de 45.000 fallecidos entre 1895 y 1897 . De ellos 13.000 correspondían a la fiebre amarilla, 2.000 a acciones armadas y el resto, 30.000 , a otras enfermedades y causas diversas.

Ciertas o no estas cifras, pues quizás en algún momento se exagere el número de bajas por enfermedades, hay que admitir los estragos causados por las epidemias en el Ejército Español. Las siguientes palabras de Larra y Cerezo, dan una idea del proceso ascendente de la mortalidad y morbosidad con respecto a otros años:

La curva estadística de mortalidad y morbosidad en los últimos veintiún años presenta en el de 1896 una curva aterradora de 7.304 fallecidos en los hospitales de fiebre amarilla; en solo doce meses suponen una mortalidad superior a la habida en los dieciséis años anteriores reunidos, puesto que la cifra de 6.385 muertos, esto es 1.024 , es menor que en solo un año, el de 1896; y tengase en cuenta que ya en el año anterior había aumentado la mortalidad en 2.796, mientras que en ninguno de los anteriores llegó a 50011.

\section{MEDIDAS SANITARIAS TOMADAS POR ESPAÑA.}

Esta difícil situación obligó a España a tomar serias medidas para disminuir el número de enfermos y mejorar la atención a éstos y a los heridos.

A raíz de un pedido de médicos y farmacéuticos hecho a la Península por el General Arsenio Martínez Campos en julio de 1895, y debido a la intensidad que tomaba la guerra, en el mes de agosto se promulgó una convocatoria por parte del Ministerio de la Guerra, a fin de cubrir plazas de estas especialidades en Cuba. Las convocatorias continuaron haciéndose durante todo el desarrollo de la guerra. Los que se presentaran a ellas debían reunir como requisitos fundamentales:

- Ser español o estar nacionalizados así.

- No pasar de 30 años.

11 LARRA Y CEREZO (1901), p. 37. 
- Tener aptitud física requerida para el Servicio Militar.

- Haber obtenido título de Dr. en algunas de las universidades oficiales del reino, y/o tener aprobado los ejercicios médicos para ello.

Si bien a lo largo de la guerra fue aumentando progresivamente el número de plazas convocadas para Cuba, no siempre existió una proporción adecuada entre el personal de Plana Mayor y los subalternos. En reiteradas ocasiones existió carencia de estos últimos, que debían cumplir sus servicios en los hospitales y las enfermerías de los distintos cuerpos y regimientos. Por otra parte, se apreciaba un elevado número de jefes, que hacían de la Sanidad Militar uno de los cuerpos con mayor cantidad de oficiales en Cuba.

Esta situación se hizo crítica en 1897 , llegando a contarse más de cuatrocientos jefes, lo que obligó al gobierno peninsular a tomar serias medidas y prestar una atención más directa a las cuestiones sanitarias. En el mes de octubre, por Real Decreto, se estableció que: "Una de las secciones que forman parte del Ministerio de la Guerra, será en lo sucesivo dirigida por un Inspector Médico de Segunda Clase, y se encargará exclusivamente a el estudio y despacho de los asuntos concernientes a la Sanidad del Ejército"12, actividad que anteriormente era ejercida por un oficial no especializado en cuestiones sanitarias.

Asimismo se autorizó a nombrar médicos civiles para que ocuparan plazas de médicos militares, debido a la insuficiencia de éstos y la imposibilidad de prestar atención sanitaria a las fuerzas que salían de operaciones.

En los momentos que pudo disponerse de suficientes médicos civiles y militares, se estableció que al menos uno de ellos saliera con los batallones de operaciones, a fin de prestar a los soldados los primeros auxilios, acción imprescindible para impedir el avance de las enfermedades. Era muy común en la época que los soldados destacados en poblaciones, cuando experimentaban algún síntoma acudieran a la enfermería y gracias a la rapidez rara vez fallecían. Sin embargo, aquel que era atacado de alguna dolencia durante la marcha, y requería ser transportado y disponer de una atención primaria, generalmente fallecía.

Además, no siempre resultaba fácil transportar a los soldados enfermos a los hospitales y las enfermerías. En una comunicación del Director del Hospital de Güines, provincia Habana, al Comandante de dicha Plaza Militar, le informaba del mal estado en que eran conducidos al hospital los convalecientes del Batallón Provisional de Canarias afectados de fiebre amarilla, algunos de los cuales morían en el trayecto a consecuencia de la demora en el traslado.

Igualmente se preocupaba por haber recibido noticias de que en el campamento quedaban más de cuarenta hombres enfermos, sin que el Jefe de Bon tomase medida

12 Periódico El Correo Militar. Madrid, 22 de octubre de 1897. 
alguna para evitar consecuencias lamentables, por lo que recomendaba el reconocimiento de la fuerza por los correspondientes facultativos “... a fin de evitar la propagación en el resto de la tropa ... y dado el caso de estar alguno afectado de dicha enfermedad sea enviado lo antes posible al Hospital" 13 .

Como otra de las medidas se decretó que los batallones expedicionarios que fueran a Cuba, llevasen un botiquín de campaña con sus respectivos arreos y accesorios, mochilas de ambulancia y camillas completas, así como que cada escuadrón llevara, independientemente, una bolsa sanitaria de grupo, una bolsa de ambulancia y dos camillas completas.

En los lugares donde había destacadas grandes cantidades de fuerza, a fin de atenuar los efectos de las epidemias, se orientó concentrar la mayor cantidad posible de material sanitario, se construyeron enfermerías a donde los soldados pudieran acudir, se hicieron zanjas de desagüe para impedir el estancamiento de las aguas, etc.

Con similares intenciones de saneamiento, en el mes de agosto de 1897 se decidió crear una Inspección General de Beneficencia y Sanidad Civil de la Isla. La actividad fundamental de esta inspección, encabezada por el Inspector General de Sanidad Militar Cesáreo Fernández de Losada, tenía por objeto mejorar la situación higiénica en el país y especialmente en la Habana, cuya bahía era foco de constantes infecciones por el precario estado en que se encontraba.

Estas últimas medidas, unidas a otras como la construcción de sanatorios, donde el soldado debilitado pudiese reponer sus fuerzas antes de reincorporarse a la campaña o regresar a la Península, quedaron casi siempre en un intento, debido, entre otras causas, a la falta de presupuesto, pues los numerosos gastos que deparaba la guerra, obligaban a emplear los recursos en otras necesidades más apremiantes, como los suministros o el envío de armamento y municiones. Además, el elevado número de soldados que requerían asistencia dificultaba la labor.

Considerando estos elementos, resulta evidente las enormes dificultades que afrontó el combatiente peninsular en Cuba para recibir una adecuada atención. Los que se encontraban distanciados de los hospitales eran atendidos en las Enfermerías Reglamentarias, creadas con el objetivo de curar a los heridos leves, así como a los que por su estado fuera imposible trasladar inmediatamente a los hospitales. Sin embargo, estas enfermerías afrontaban grandes dificultades con la medicación y la disponibilidad de médicos.

Entre enfermerías, clínicas y hospitales habían en Cuba, en junio de 1898, un total de 69, distribuidas por el país de la siguiente forma:

\footnotetext{
13 Comunicación del Director del Hospital Militar de Güines al Jefe de la Plaza Militar. 10 de noviembre de 1897. Leg. 233, Nº 6. Fondo Asuntos Políticos. Archivo Nacional de Cuba.
} 
LA SANIDAD MILITAR DEL EJÉRCITO ESPAÑOL EN LA GUERRA DE 1895 EN CUBA

$\begin{array}{lccc}\text { Provincia } & \text { Hospitales } & \text { Clínicas } & \text { Enfermerías } \\ \text { P. del Río } & 3 & 5 & 3 \\ \text { La Habana } & 9 & 3 & 5 \\ \text { Matanzas } & 2 & 1 & - \\ \text { Las Villas } & 8 & 5 & - \\ \text { Camagüey } & 3 & 3 & - \\ \text { Oriente } & 9 & 12 & -\end{array}$

Es necesario advertir que no siempre fueron tantos el número de estos establecimientos. En un principio no eran suficientes por lo que reiteradamente se acudió a la máxima autoridad en la Isla, a fin de que dispusiera la construcción de nuevos hospitales para dar respuesta a la demanda de camas.

Al estallar la guerra, existían hospitales en La Habana, Santiago, Santa Clara y Puerto Príncipe. En abril de 1895 se establecieron los de Manzanillo, Holguín y Bayamo, y hasta agosto del mismo año se construyeron los de Victoria de la Tunas, Santiago de las Vegas, Ciego de Avila, Mayarí, Sancti Spíritus, Gibara, Remedios y Guantánamo, así como las enfermerías de Nuevitas, Santa Cruz del Sur, Güaímaro, Arroyo Blanco, Songo y San Luis.

En el período de septiembre a diciembre del mismo año 1895 se crearon los hospitales de Sagua de Tánamo, Sagua la Grande, Colón, Veguitas, Cauto Embarcadero, Jiguaní, Trinidad y Baracoa.

En 1896 se establecieron hospitales en Matanzas, San Antonio de los Baños, Güines, Maniabón, Mariel, Pinar del Rio, y las enfermerías de Guanajay, Palma Soriano, San Andrés, Consolación del Sur, Artemisa, Marianao y Cárdenas. Al año siguiente se construyeron hospitales en Madruga, Güira, Artemisa, Bahía Honda y El Cobre, entre otros, hasta completar la cifra de 69, cantidad referida a 1898.

Algunos de estos hospitales y enfermerías eran construidos con carácter provisional, ante la necesidad de alojar a los soldados necesitados.En ocasiones se utilizaban para este propósito antiguos cuarteles de Caballería o Infantería, razón por la cual no reunían las condiciones adecuadas para la atención de enfermos y heridos.

Las recomendaciones más difundidas en la época para la construcción de hospitales, planteaban el establecimiento de éstos en lugares altos y frescos. En cuanto a las características que debían reunir pueden tomarse como ejemplo las orientaciones dadas por el Jefe de la Plaza de Bayamo para la construcción de un hospital en dicho lugar: barracones de mampostería de $60 \mathrm{~m}$ de largo por 10 de ancho, de suficiente altura y ventilación alta y baja para garantizar la higiene, el suelo a pie y medio de altura sobre el terreno, cada barracón debía contar con una zona dividida por un tabique, desde el techo hasta el suelo, para alojar a los enfermos infecciosos; de ser posible 
se construiría un aljibe para recoger las aguas del tejado y ser vertidas en un depósito, evitando de esa forma su estancamiento y, por otra parte, facilitar su aprovechamiento.

Sin embargo, no siempre pudieron cumplirse estas recomendaciones pues las necesidades aumentaban cada vez más en correspondencia con las disponibilidades; esto obligaba a acudir a los lugares existentes sin detenerse a precisar si reunían o no condiciones para el objeto a que eran destinados; lo esencial era la capacidad: mientras más amplios eran mejor, ya que ello daba la posibilidad de colocar, improvisadamente, el mayor número de catres de madera, a fin de que quedasen dispuestos para alojar tantos soldados como fuera posible.

Por otra parte, el costo de construcción de un barracón era elevado: uno para 200 personas costaba entre 600 y 650 pesos $^{14}$.

Varios hospitales se vieron afectados por la gran afluencia de enfermos y heridos como lo demuestran los casos del Alfonso XIII y el de San Ambrosio en La Habana, y el de Cienfuegos en la ciudad del mismo nombre. En este último, según relataba Manuel Corral, quien formó parte del Batallón de Burgos, hubo que duplicar el número de catres en cada sala y no siendo suficiente esto, se colocaron catres bajo los cobertizos, llegando un momento en que ya no fue posible admitir más soldados, y por tanto las autoridades se vieron en la necesidad de alojar a los más necesitados en almacenes de azúcar, sin condiciones para esta función por ser un seguro foco de infecciones.

En el hospital Alfonso XIII de la Habana, construido con las condiciones adecuadas y para una capacidad de 500 camas, 800 en caso de apuro, en ocasiones se llegó a recibir más de 2.000 soldados, sin desechar la probabilidad de que esta cifra aumentara.

El de San Ambrosio, por su precario estado había sido cerrado, pero las necesidades determinaron su reapertura. Los primeros soldados que arribaron fueron colocados en la planta alta, que era la menos infecciosa, con una capacidad para cerca de 500 personas; cuando este nivel estuvo cubierto, el resto fue alojado en los sótanos, con un estado higiénico deplorable.

Asimismo fue necesario "habilitar" los almacenes de Regla, edificios de madera sobre la inmunda bahía habanera, y que eran utilizados como depósitos de azúcar en tiempos de zafra. Este sitio poseía un pobre iluminación y sus condiciones de ventilación eran pésimas, por lo que se convertían en verdaderos caldos de cultivo para la fiebre amarilla y otras epidemias en general.

Algunos estudios realizados en la época por un doctor español de apellido Plaza ${ }^{15}$ recomendaban que los hospitales no fueran construidos en sitios bajos ni cercanos a la costa, por su propensión a desarrollar focos infecciosos, en tanto los que eran

\footnotetext{
14 Un barracón para Hospital en San Felipe, la Habana, costaba 624 pesos y tenía capacidad par 100 personas. Leg. 232, $\mathrm{N}^{\circ}$ 19. Fondo Asuntos Políticos. Archivo Nacional de Cuba.

15 Este médico estuvo prestando sus servicios en Cuba durante gran parte del año 1896 y sus estudios fueron publicados en varios números del periódico El Imparcial.
} 
construidos en sitios altos abarataban el tratamiento de las personas recluidas y facilitaban su más rápida recuperación.

Si bien era cierto que la construcción de los hospitales era más cara teniendo en cuenta todas las dependencias necesarias para su adecuado funcionamiento, también lo era que los resultados obtenidos en la recuperación de los incapacitados, lo hacían más rentable que aquellos sitios que eran adaptados para ser utilizados como hospitales.

Cifras aparecidas en el propio periódico durante el primer trimestre de 1897 corroboran estos planteamientos, al ofrecer los siguientes datos de asistidos y muertos en cuatro recintos hospitalarios, los dos primeros en sitios elevados y los otros en zonas bajas y cercanas a la costa:

$\begin{array}{lcc}\text { Hospital } & \text { Asistidos } & \text { Muertos } \\ \text { Alfonso XIII } & 262 & 34 \\ \text { Madera } & 108 & 15 \\ \text { Regla } & 158 & 45 \\ \text { San Ambrosio } & 47 & 19\end{array}$

El precario estado de algunos hospitales se veía agravado frecuentemente por la excesiva cantidad de convalecientes, lo que dificultaba su adecuada atención, puesto que a cada sanitario le correspondía atender a mayor cantidad de personas que la habitualmente asignada; unido a esto, los farmacéuticos tenían que triplicar, y a veces más, la preparación de las dosis a suministrar a los enfermos, lo cual creaba innumerables problemas.

La alimentación también originaba dificultades; las personas recluidas en los hospitales necesitaban, ante todo, una alimentación equilibrada y reforzada, pero al ser cada vez mayor el número de personas hospitalizadas comenzaron a crearse problemas con los víveres, lo que provocó que los alimentos a consumir no siempre fueran suficientes. El enfermo, generalmente, recibía en el desayuno una pequeña ración de café con leche y un panecillo que rara vez sobrepasaba los 50 gramos; en el almuerzo un cocido con un pedazo de carne o tocino por sustancia, y para la comida una sopa, que a veces se acompañaba de pan.

Esta situación se agravó en la medida en que avanzó la guerra y comenzaron a afrontarse serios problemas con los suministros: aumentaban las necesidades de abastecimientos y los comerciantes se negaban a venderle al ejército, pues a causa del retraso en las pagas no disponían de dinero. Ejemplo de lo anterior fue el cierre del hospital de Santiago de las Vegas en 1898.

El suministro de medicamentos también presentó algunas irregularidades, pues no siempre era posible satisfacer todos los pedidos. Desde el estallido de la guerra hasta 
octubre de 1896 fueron enviados a Cuba $303.515 \mathrm{~kg}$. de medicamentos en 3.049 cajas con un costo aproximado de dos millones de pesetas ${ }^{16}$.

Después de haber sido 1896 un año crítico para la sanidad por el aumento de los necesitados, comenzaron a escasear los medicamentos. A mediados de 1897 fueron pedidas insistentemente al Ministerio de la Guerra medicinas tan comunes como quinina, yodo, gasas, sulfato químico, ácido bismuto, entre otros. En 1898 estos medicamentos eran solicitados con carácter urgente.

Según un informe del Inspector General de Sanidad Militar en Cuba, Cesáreo Fernández de Losada, hecho público en diciembre de 1897, se había producido una imprevisión por parte de las autoridades sanitarias en la Isla y en la Metrópoli: no se previó la posibilidad de que la campaña se dilatara y que por tanto fuera necesario crear nuevos hospitales, algunos de los cuales no reunían las condiciones mínimas.

Esta situación se hizo más compleja con la extensión de la guerra, territorialmente, hasta Occidente, pues al no haber abarcado la campaña anterior provincias como Pinar del Río y Matanzas, se desconocían las condiciones de estas regiones, altamente favorables para contraer enfermedades, debido a la existencia de varias zonas pantanosas.

Asimismo reconocía el Dr. Fernández de Losada que era de todo punto imposible lograr una aclimatación de todas las fuerzas que marchaban a Cuba, debido a la premura con que éstas partían, pero, sin embargo, podían haberse atenuado los efectos debilitantes del clima sobre ellos. Consideraba que de haberse garantizado la utilización de filtros de agua se habría evitado que el soldado ingiriera aguas estancadas y en mal estado, con los trastornos que ello provocaba. Por otra parte, recomendaba que para evitar el total agotamiento de las fuerzas existentes en Cuba por las continuas marchas y contramarchas, se aumentara el contingente de fuerzas montadas.

Respecto a los problemas de alimentación, al ser imposible suministrar al soldado la suficiente cantidad de comida fresca para mantener la salud, planteaba la necesidad de que éste consumiera abundantes cantidades de frutas y vegetales, procurando asimismo que a falta de carne fresca, al menos la consumiese enlatada.

Igualmente reconocía lo nefasto que había sido para la tropa pernoctar a la intemperie, con una vestimenta propicia al enfriamiento del organismo, pues tanto lo uno como lo otro era favorable para contraer enfermedades. Finalmente reconocía que la falta de construcción de sanatorios, donde lo primordial fuera la higiene, la ventilación y una alimentación adecuada, impedía al soldado disponer de un lugar donde reponer sus fuerzas, teniendo que ser repatriado a la Península en un estado sanitario deplorable, resultando más económico la construcción de estos lugares que todos los gastos ocasionados por el transporte de soldados a la Metrópoli.

16 Periódico El Correo Militar. Madrid, 15 de octubre de 1896. 
De todo lo expuesto resulta evidente la certeza de estos planteamientos; sólo tuvieron como límite la tardanza con que fueron realizados. De haberlos hecho en los inicios de la campaña, y si las respectivas administraciones, peninsular e insular, les hubiesen prestado la atención que merecían, muchos males habrían podido evitarse.

La subestimación por parte del gobierno español del proceso independentista reiniciado el 24 de febrero de 1895, propició la aceleración de los acontecimientos y la imposibilidad de resolver múltiples problemas que después se presentaron, entre ellos los afrontados por la Sanidad Militar, que dieron lugar a un considerable incremento de bajas en este cuerpo, ya fuese por enfermedades, ya por heridas recibidas en combate.

\section{FUENTES}

Libros

- Baraja Montana, Manuel (1979): La Guerra de Cuba a través del Diario de Cádiz: 1895 1898. Del Grito de Baire al hundimiento del Maine. Edit. por Industrias Gráficas Gaditanas S.A., Cádiz.

- CORRAL, Manuel (1899): ¡El desastre!. Memorias de un voluntario en la Campaña de Cuba. Tip. Moderna, Barcelona.

- HERNÁNDEZ Poggio, Ramón (1976): Aclimatación e higiene de los europeos en Cuba. Imprenta de la Revista de Sanidad Militar, Cádiz.

- LARRA y CEREZo, Angel de (1901): Campaña sanitaria en la Guerra de Cuba. Apuntes estadísticos relativos al año 1896. Imprenta Ricardo Rojas, Madrid.

- STOCKer, M (1898): "La fiebre amarilla" en Revista de Sanidad Militar, $1^{\circ}$ de noviembre, Año X, Madrid.

Publicaciones

- Periódico El Correo Militar. 1895-1898.

- Periódico El Imparcial. 1895-1898.

- Periódico La Época. 1895-1898.

— Revista de Sanidad Militar. 1896-1898.

Documentos

- Fondo Asuntos Políticos. Archivo Nacional de Cuba. 